\title{
Evaluation of the factors affecting the health literacy levels of patients admitted to family health centers*
}

\author{
ÖZGÜL ÖRSAL $L^{1, A-F}$, PINAR DURU 2, A, C-F , ÖZLEM ÖRSAL 2, A, C-F, \\ ORCID ID: 0000-0002-1315-7483 ORCID ID: 0000-0002-3471-1383 ORCID ID: 0000-0002-4494-8587 \\ KAZIM TIRPAN ${ }^{3, A, B, F}$, ABDULLAH ÇULHACI ${ }^{4, A, B, E, F}$ \\ ORCID ID: 0000-0001-5275-2712
}

${ }^{1}$ Social Sciences Institute, Department of Business/Management Organization, Eskişehir Osmangazi University,

Eskisehir, Turkey

${ }^{2}$ Department of Public Health Nursing, Eskişehir Osmangazi University, Eskisehir, Turkey

${ }^{3}$ Kemal Nurhan Mani Family Health Center, Eskisehir, Turkey

${ }^{4}$ Yeni Family Health Center, Eskisehir, Turkey

A - Study Design, B - Data Collection, C - Statistical Analysis, D - Data Interpretation, E - Manuscript Preparation, F - Literature Search, G - Funds Collection

Summary Background. Health literacy is a holistic structure of belief systems and personal philosophy, which consists of functional, critical, and communication skills that explain medical decision-making.

Objectives. The study aimed to determine the levels of health literacy and the variables that affect it in patients who were admitted to family health centers (FHCs).

Material and methods. This cross-sectional study, which was performed in a Central Anatolia City (Eskisehir), included patients who were admitted to FHCs $(n=1,055)$ between May and June 2017. Data were collected using a questionnaire consisting of 27 questions about the patient's sociodemographic characteristics, the resources that are available to them with health-related information, their accessibility to this information and healthcare institutions, and the Turkish Health Literacy Scale.

Results. The mean health literacy score of the participants was $29.57 \pm 9.27$. Health literacy levels of participants were problematic in $38.6 \%$ and inadequate in $27.5 \%$ of the subjects. According to the results of logistic regression analysis, the probability of having a high level of health literacy in FHC patients was halved for each age increase; it increased by 2.5 -fold for graduates of secondary education, by 3.1-fold for high-school graduates, by 3.3-fold for those holding an undergraduate degree, by 1.5 -fold for participants who did not suffer from a disease that requires regular medication, by 2.7 -fold for individuals most commonly admitted to private hospitals in case of any health problem or disease, and by 0.6 -fold for subjects who did not see a family physician in the last six months. Conclusions. The health literacy level of the population of Eskisehir is affected by unchangeable and changeable factors. Key words: health literacy, health services, patients, primary health care, public health, population health.

Örsal Ö, Duru P, Örsal Ö, Tırpan K, Çulhacı A. Evaluation of the factors affecting the health literacy levels of patients admitted to family health centers. Fam Med Prim Care Rev 2021; 23(3): 330-336, doi: https://doi.org/10.5114/fmpcr.2021.108199.

\section{Background}

Health literacy is linked to literacy and entails people's knowledge, motivation, and competences to access, understand, appraise, and apply health information in order to make judgments and decisions in everyday life concerning healthcare, disease prevention, and health promotion to maintain or improve one's quality of life [1]. Health literacy can be considered a holistic construct composed of functional, critical, and communicative skills, with the goal of understanding how belief systems and personal philosophy affect medical decision-making [2]. Health literacy is a holistic structure of belief systems and personal philosophy, which consists of functional, critical, and communication skills that explain medical decision-making.

Low health literacy is associated with negative health outcomes such as poorer use of preventive healthcare services, higher healthcare utilization and expenditures, increased health disparities, occupational accidents, the possibility of complications and hospitalizations, high mortality rates, a reduced ability to use medications appropriately, dissatisfaction with health services, non-compliance with treatment, decreased quality of life, and reduced self-management [3-6]. Higher health literacy means better individual health outcomes at all levels of protection and among the general population. Therefore, it is one of the priority issues in terms of public health [7]. Today, however, unhealthy lifestyles are actively marketed and insurance companies and healthcare providers are shifting the burden of health maintenance to the consumer. For this reason, even for the most well-educated people, the understanding of health systems and making informed decisions about health are increasingly difficult $[1,8]$.

Health literacy is mentioned as a key priority on the European Union agenda and monitoring the level of health literacy can support professional and political decision-making in improving it [9]. In contrast, there is another view that does not recommend screening health literacy skills in the clinic routinely, as this does not improve the health outcomes of patients. Those who adopt this view consider the use of universal health literacy measures as sufficient to provide accessible and comprehensible information to all individuals and to achieve optimal health outcomes regardless of literacy or education [10].

The health literacy level of patients has an impact on the patients' perception of the overall quality of primary care/basic health

*Previous presentations: This study was previously presented as an oral presentation at the $1^{\text {st }}$ International $2^{\text {nd }}$ National Public Health Nursing Congress in Ankara, Turkey in 2018. 
services [11]. However, little is still known about the variables that affect health literacy and the health literacy levels of patients presenting to primary healthcare clinics. This study is thought to be important in terms of creating a database that will contribute to the planning of strategies to be followed and policies to be developed in order to improve health literacy. It is also believed that by contributing to the future policies for improving health literacy, low health literacy will be effective in guiding the prevention of negative health outcomes for the individual and community, and indirectly in eliminating the health disparities in the primary care system. This study was performed to determine the health literacy levels of the patients who were admitted to family health centers (FHCs) and variables affecting health literacy levels.

\section{Objectives}

The aim of the study was to determine the levels of health literacy and the variables that affect it in patients who were admitted to FHCs.

\section{Material and methods}

This is a cross-sectional study conducted on individuals ( $n$ $=1,055$ ) admitted to FHCs in a province in the Central Anatolia region of Turkey in 2017. Primary healthcare services in Turkey are carried out by family physicians who serve in FHCs and cooperate in teams. An average of 3,000 individuals are registered to each family physician. The universe of the study consists of a total of 718,750 individuals $(417,170$ people registered to 120 family physicians in 30 FHCs located in the Odunpazari district and 301,580 registered to 86 family physicians in 26 FHCs in the Tepebasi district). The sample size was calculated to be 1,065 with a $95 \%$ confidence interval and a $3 \%$ error margin. The sample size was stratified according to the number of family physicians and included 5-6 people per family physician (Figure 1). To be able to represent the entire population and to eliminate the impact of institutional preferences on the findings of the study, individuals who did not directly go to the FHCs to receive polyclinic services but were admitted for reasons such as pregnancy follow-up, vaccination, and medical health reports, etc. were included in the sampling. Among the applications made in accordance with these criteria, 5-6 people per family physician were included in the sample with the simple random sampling method by using a simple random number table. The sample size consisted of 1,055 individuals.

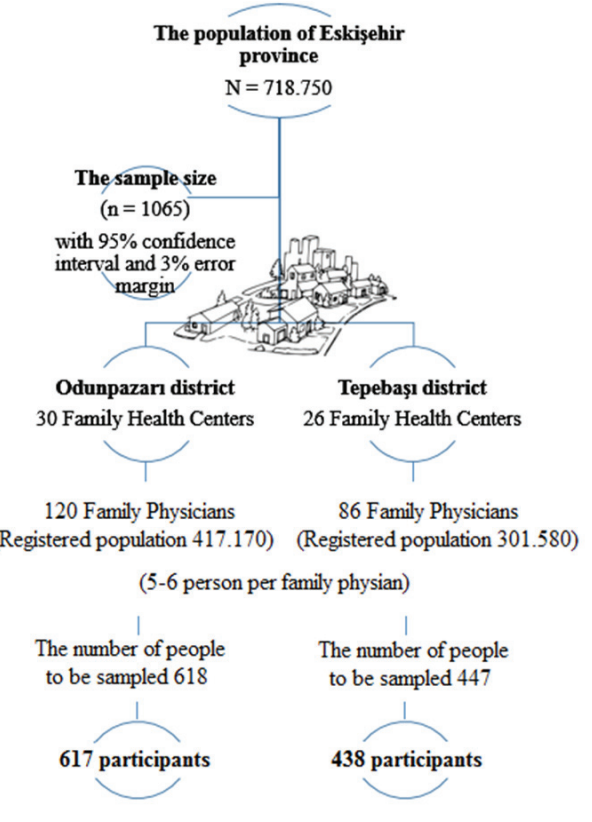

Figure 1. Participant flow chart
Approval was obtained from the Non-Interventional Clinical Trials Ethics Committee (80558721/135) and the Public Health Directorate (14198468-772.02). The data from the analysis of the relationship between health literacy, primary care satisfaction levels, and health awareness of the patients were previously presented in another article.

\section{Data collection tools}

The questionnaire form consists of two parts: sociodemographic characteristics and HLS-TR. The first part of the questionnaire consists of 27 items about some sociodemographic characteristics (e.g. age, gender, marital status, educational status, working status, social security, the place where one lived for the longest period, the perception of monthly income of the family, sources of health information, and access to information and health institutions [e.g. perception of general health, non-communicable diseases, the presence of a disease requiring regular use of medication, or admission to the family physician within the last six months except the present admission]). The second part included items about the HLS-TR.

Turkish health literacy scale (HLS-TR): The HLS-TR is a new 32-item health literacy scale, adapted from the conceptual framework developed by the European Health Literacy Survey (HLS-EU) consortium. The lowest possible score is 0 and the highest score is 50 . The health literacy level was assessed in four categories according to the score obtained, where 0-25 points means inadequate, $26-33$ points means problematic/limited, 34-42 points means adequate, and $43-50$ points means excellent. The Cronbach alpha coefficient of the scale was found to be 0.92 [12], which was 0.96 in this study.

\section{Statistical analyses}

In data analysis, in addition to descriptive statistics such as frequency, mean, standard deviation etc., the Mann-Whitney $U$ test in groups with two non-parametric, independent variables and the Kruskal-Wallis test in groups with more than two independent variables were used. The premises of multiple linear regression analysis were not met, so binary logistic regression analysis was used to predict the relationship between the predictors (our independent variables) and the predicted variable (dependent variable). In binary logistic regression analysis, a dependent variable for health literacy level was included in the model and coded as "inadequate (0)" for inadequate and problematic health literacy or "adequate (1)" for adequate and excellent health literacy. The statistical significance level was set at $p<0.05$.

\section{Results}

In the study group of 1,055 individuals, $76.3 \%(n=805)$ were female; the mean age was $41.89 \pm 16.21$ years (min: 18.00 ; max: 90.00). Among the participants, $81.7 \%(n=862)$ were married, $35.4 \%(n=373$ ) were elementary school graduates, and $73.2 \%$ ( $n=772$ ) were unemployed. Of the study group, $4.9 \%(n=52)$ had no social security. While $13.5 \%$ of the participants $(n=142)$ stated that they lived in a village/town for most of their lives, $69.1 \%$ ( $n=729$ ) had expenses equal to their families' monthly incomes; $23.7 \%$ ( $n=250)$ of the participants reported that their monthly income was less than their expenses (Table 1).

The participants' general health status was evaluated as average in $22.7 \%(n=239)$ of cases and as poor in $4.1 \%(n=43)$. In the study group, $36 \%(n=380)$ had a disease that requires regular medication; $14.1 \%(n=149)$ had hypertension, $9.4 \%$ $(n=99)$ had diabetes, 3.6\% $(n=38)$ had heart disease, and 3.6\% $(n=38)$ had asthma (Table 2$)$. Over half $(55.5 \%[n=585])$ of the participants reported that the $\mathrm{FHC}$ was the first referral site for any health problem or disease, while $45.2 \%(n=477)$ reported that the FHC was the most frequently visited health institution (Table 3). The study group was admitted to a health institution $8.02 \pm 9.52$ times/year (min: 1 ; $\max$ : 175) on average for any health problems (disease, examination, prescription, etc.). 


\begin{tabular}{|c|c|c|c|}
\hline \multirow[t]{2}{*}{ Health literacy levels } & \multirow[t]{2}{*}{$n$} & \multicolumn{2}{|c|}{ The scores of the HLS-TR scale } \\
\hline & & \multicolumn{2}{|c|}{ Mean \pm SD } \\
\hline $\begin{array}{l}\text { Inadequate } \\
\text { Problematic } \\
\text { Adequate } \\
\text { Excellent }\end{array}$ & $\begin{array}{l}290 \\
407 \\
261 \\
97\end{array}$ & \multicolumn{2}{|l|}{$29.57 \pm 9.27$} \\
\hline \multirow{2}{*}{ Variables } & \multirow[t]{2}{*}{$n$} & \multicolumn{2}{|c|}{ The scores of the HLS-TR scale } \\
\hline & & $\begin{array}{l}\text { Median } \\
(\min -\max )\end{array}$ & $\begin{array}{l}\text { Test Value } \\
\mathrm{z} / \mathrm{KW} ; \boldsymbol{p}\end{array}$ \\
\hline $\begin{array}{l}\text { Gender } \\
\text { female } \\
\text { male }\end{array}$ & $\begin{array}{l}805 \\
250\end{array}$ & $\begin{array}{l}30.20(0.00-50.00) \\
30.15(0.00-50.00)\end{array}$ & $102.397 ; 0.674$ \\
\hline 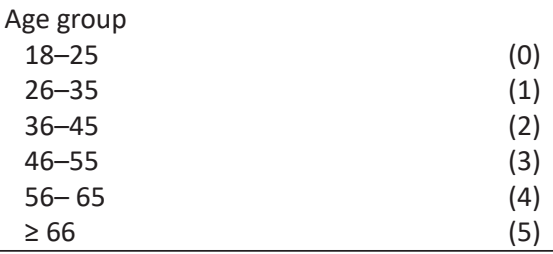 & $\begin{array}{l}169 \\
288 \\
204 \\
140 \\
139 \\
115\end{array}$ & $\begin{array}{l}31.72(0.00-50.00) \\
31.77(6.55-50.00) \\
41.40(0.00-50.00) \\
29.09(0.00-50.00) \\
27.60(0.00-48.39) \\
25.00(0.00-47.40) \\
\end{array}$ & $90.379 ; 0.000$ \\
\hline Intergroup comparison & \multicolumn{3}{|c|}{$\begin{array}{l}(5-0),(5-1),(5-3),(4-0),(4-1),(4-2),(3-1),(3-2)=>p=0.000 \\
(3-0) p=0.003\end{array}$} \\
\hline $\begin{array}{l}\text { Marital status } \\
\text { married } \\
\text { single }\end{array}$ & $\begin{array}{l}862 \\
193\end{array}$ & $\begin{array}{l}30.20(0.00-50.00) \\
30.72(0.00-50.00) \\
\end{array}$ & $84.733 ; 0.685$ \\
\hline $\begin{array}{l}\text { Education status } \\
\text { elementary school } \\
\text { secondary school } \\
\text { high school } \\
\text { university } \\
\text { master's degree and above }\end{array}$ & $\begin{array}{l}373 \\
173 \\
270 \\
217 \\
22 \\
\end{array}$ & $\begin{array}{l}26.54(0.00-50.00) \\
29.44(0.00-50.00) \\
32.24(3.09-50.00) \\
33.33(7.84-50.00) \\
35.41(19.27-50.00)\end{array}$ & $143.268 ; 0.000$ \\
\hline Intergroup comparison & \multicolumn{3}{|c|}{$\begin{array}{l}(0-1) p=0.003 ;(0-2) p=0.000 ;(0-3) p=0.000 ;(0-4) p=0.000 \\
(1-2) p=0.000 ;(1-3) p=0.000 ;(1-4) p=0.003\end{array}$} \\
\hline $\begin{array}{l}\text { Working status } \\
\text { employed } \\
\text { unemployed }\end{array}$ & $\begin{array}{l}283 \\
772\end{array}$ & \begin{tabular}{|l|}
$32.81(0.00-50.00)$ \\
$29.31(0.00-50.00)$
\end{tabular} & $82.925 ; 0.000$ \\
\hline $\begin{array}{l}\text { Social security } \\
\text { yes } \\
\text { no }\end{array}$ & $\begin{array}{l}1003 \\
52\end{array}$ & $\begin{array}{l}30.20(0.00-50.00) \\
28.38(0.00-48.44)\end{array}$ & $28.865 ; 0.193$ \\
\hline $\begin{array}{l}\text { The place lived for the longest period } \\
\text { village/town } \\
\text { city center } \\
\text { capital/metropolis }\end{array}$ & $\begin{array}{l}142 \\
614 \\
299\end{array}$ & $\begin{array}{l}26.98(0.00-50.00) \\
30.72(0.00-50.00) \\
30.72(0.00-50.00)\end{array}$ & $13.162 ; 0.001$ \\
\hline Intergroup comparison & \multicolumn{3}{|c|}{$(0-1) p=0.002 ;(0-2) p=0.002$} \\
\hline $\begin{array}{l}\text { Perception of monthly income of the family } \\
\text { income is less than expenses } \\
\text { equal } \\
\text { more }\end{array}$ & $\begin{array}{l}250 \\
729 \\
76\end{array}$ & $\begin{array}{l}29.62(0.00-50.00) \\
30.20(0.00-50.00) \\
31.39(0.00-50.00) \\
\end{array}$ & $5.870 ; 0.053$ \\
\hline Total & 1055 & $30.20(0.00-50.00)$ & \\
\hline
\end{tabular}

\begin{tabular}{|c|c|c|c|c|}
\hline \multirow[t]{2}{*}{ Variables } & & \multirow[t]{2}{*}{$n$} & \multicolumn{2}{|c|}{ The scores of the HLS-TR scale } \\
\hline & & & \begin{tabular}{|l|} 
Median \\
(min-max) \\
\end{tabular} & $\begin{array}{l}\text { Test value } \\
\mathrm{z} / \mathrm{KW} ; \boldsymbol{p} \\
\end{array}$ \\
\hline $\begin{array}{l}\text { Perception of general he } \\
\text { excellent/fairly good } \\
\text { good } \\
\text { average/poor }\end{array}$ & $\begin{array}{l}\text { (0) } \\
(1) \\
(2)\end{array}$ & $\begin{array}{l}219 \\
554 \\
282 \\
\end{array}$ & \begin{tabular}{|l|}
$32.29(0.00-50.00)$ \\
$30.22(0.00-50.00)$ \\
$28.22(0.00-50.00)$ \\
\end{tabular} & $32.838 ; 0.000$ \\
\hline \multicolumn{2}{|l|}{ Intergroup comparison } & \multicolumn{3}{|c|}{$(2-1) p=0.001 ;(2-0) p=0.000 ;(1-0) p=0.005$} \\
\hline $\begin{array}{l}\text { Diabetes } \\
\text { yes } \\
\text { no } \\
\end{array}$ & & $\begin{array}{l}99 \\
956 \\
\end{array}$ & $\begin{array}{l}27.16(2.38-48.39) \\
30.72(0.00-50.00) \\
\end{array}$ & $37.659 ; 0.001$ \\
\hline $\begin{array}{l}\text { Heart disease } \\
\text { yes } \\
\text { no }\end{array}$ & & \begin{tabular}{|l}
38 \\
1017
\end{tabular} & $\begin{array}{l}28.38(6.67-47.40) \\
30.20(0.00-50.00)\end{array}$ & $16.279 ; 0.099$ \\
\hline
\end{tabular}




\begin{tabular}{|c|c|c|c|}
\hline \multirow[t]{2}{*}{ Variables } & \multirow[t]{2}{*}{$n$} & \multicolumn{2}{|c|}{ The scores of the HLS-TR scale } \\
\hline & & $\begin{array}{l}\text { Median } \\
\text { (min-max) }\end{array}$ & $\begin{array}{l}\text { Test value } \\
z / \mathrm{KW} ; \boldsymbol{p} \\
\end{array}$ \\
\hline $\begin{array}{l}\text { Hypertension } \\
\text { yes } \\
\text { no }\end{array}$ & $\begin{array}{l}149 \\
906\end{array}$ & $\begin{array}{l}25.00(0.00-50.00) \\
30.72(0.00-50.00)\end{array}$ & $44.699 ; 0.000$ \\
\hline $\begin{array}{l}\text { Renal disease } \\
\text { yes } \\
\text { no }\end{array}$ & $\begin{array}{l}7 \\
1048 \\
\end{array}$ & $\begin{array}{l}22.39(8.67-42.19) \\
30.20(0.00-50.00)\end{array}$ & $3.335 ; 0.679$ \\
\hline $\begin{array}{l}\text { Asthma } \\
\text { yes } \\
\text { no }\end{array}$ & $\begin{array}{l}38 \\
1017\end{array}$ & $\begin{array}{l}28.12(0.00-49.48) \\
30.20(0.00-50.00)\end{array}$ & $17.255 ; 0.262$ \\
\hline $\begin{array}{l}\text { A disease requiring regular use of medication } \\
\text { yes } \\
\text { no }\end{array}$ & $\begin{array}{l}380 \\
675\end{array}$ & $\begin{array}{l}28.12(0.00-50.00) \\
30.72(0.00-50.00)\end{array}$ & $149.619 ; 0.000$ \\
\hline $\begin{array}{l}\text { Admission to the family physician within the } \\
\text { previous six months, excluding the present } \\
\text { admission } \\
\text { yes } \\
\text { no }\end{array}$ & $\begin{array}{l}896 \\
159 \\
\end{array}$ & $\begin{array}{l}30.10(0.00-50.00) \\
32.29(0.00-50.00)\end{array}$ & $80.970 ; 0.006$ \\
\hline Total & 1055 & $30.20(0.00-50.00)$ & \\
\hline
\end{tabular}

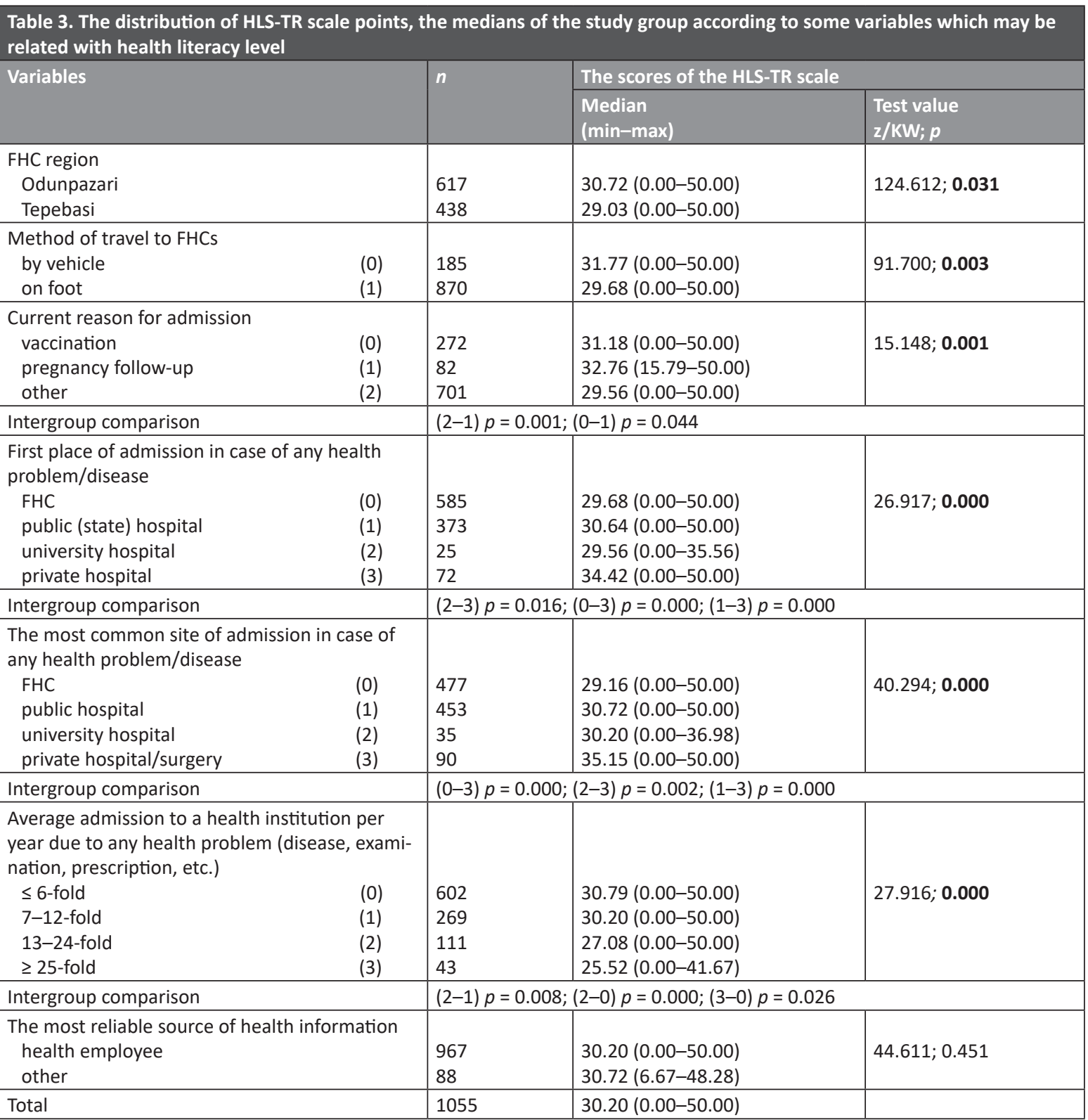




\begin{tabular}{|c|c|c|c|c|c|c|c|}
\hline \multirow[t]{2}{*}{ Variables } & \multirow[t]{2}{*}{ B } & \multirow[t]{2}{*}{ SH } & \multirow[t]{2}{*}{ Wald } & \multirow[t]{2}{*}{$p$} & \multirow[t]{2}{*}{$\operatorname{Exp}(B)$} & \multicolumn{2}{|c|}{$\begin{array}{l}95 \% \text { C.I. } \\
\operatorname{Exp}(B)\end{array}$} \\
\hline & & & & & & Min & Max \\
\hline Age & -0.016 & 0.006 & 6.065 & 0.014 & 0.985 & 0.972 & 0.997 \\
\hline Secondary school & 0.923 & 0.210 & 19.381 & 0.000 & 2.516 & 1.668 & 3.794 \\
\hline High school & 1.141 & 0.226 & 25.485 & 0.000 & 3.131 & 2.010 & 4.877 \\
\hline University & 1.203 & 0.489 & 6.064 & 0.014 & 3.331 & 1.278 & 8.679 \\
\hline $\begin{array}{l}\text { Presence of a disease requiring regular use of medication } \\
\text { (Reference = none) }\end{array}$ & 0.422 & 0.207 & 4.167 & 0.041 & 1.525 & 1.017 & 2.287 \\
\hline $\begin{array}{l}\text { Favoring private hospital admission in case of any health } \\
\text { problem/disease }\end{array}$ & 1.013 & 0.414 & 5.987 & 0.014 & 2.754 & 1.223 & 6.198 \\
\hline $\begin{array}{l}\text { Admission made to the family physician within the last } 6 \\
\text { months except the present admission (Reference = none) }\end{array}$ & -0.482 & 0.192 & 6.009 & 0.014 & 0.618 & 0.420 & 0.908 \\
\hline
\end{tabular}

The majority of the participants (89.4\% [ $n=896])$ reported that they had seen their family physician for some reason in the previous six months, and $91.7 \%(n=967)$ stated that the most reliable source of health information was a healthcare worker. According to the assessment made by the HLS-TR scale, the mean health literacy score of the participants was $29.57 \pm 9.27$ (median: 30.20; min: 0.00; max: 50.00). The health literacy levels of the participants were problematic in $38.6 \%$ of the subjects $(n=407)$ and inadequate in $27.5 \%(n=290)$ (Table 3$)$.

In our study, there was no relationship between literacy levels and gender, marital status, social security, perception of monthly income of the family (Table 1), diagnosis of heart disease, diagnosis of kidney disease, diagnosis of asthma (Table 2), or the most reliable source of health-related information (Table 3 ) [for each; $p>0.005$ ].

Higher health literacy levels were observed in the 36-45-year-old age group, those who hold a master's or higher degree, those who are employed, those who live in the city center or a capital/metropolis (Table 1), those who perceive their general health status as excellent/fairly good, those who do not have a disease that require regular medicine use, those who are not diagnosed with diabetes or hypertension, those who were admitted to a private hospital first for some health problem or disease, those who were most frequently admitted to a private hospital/clinic, those who were admitted to a health facility on average $\leq 6$ times a year due to any health problems (Table 2), those who were admitted to FHCs in the Odunpazari district, those who travelled to the $\mathrm{FHC}$ by vehicle, those who presented to FHCs due to pregnancy follow-up, and those who had not seen a family physician in the previous six months except for the current admission (Table 3) [for each; $p<0.05$ ].

In the multivariate analysis, binary logistic regression analysis was used to determine the extent to which the variables that significantly correlated with health literacy predicted the level of health literacy. It was observed that the model could explain $16.4 \%$ of the level of health literacy (Nagelkerke $\mathrm{R}^{2}=$ $0.164)$. The Hosmer-Lemeshow test indicated that this model is a good model $(p>0.05)$. The results of the regression analysis are shown in Table 4.

\section{Discussion}

The health literacy of all individuals in the community is of utmost importance for a sustainable health system [13]. This study was completed with a total of 1,055 people (617 registered to 120 family physicians in the Odunpazari district and 438 registered to 86 family physicians in the Tepebasi district) in a province in Central Anatolia region of Turkey. The deviations in gender (76.3\% female), marital status ( $81.7 \%$ married), and education (35.4\% primary school) were due to the practice of including individuals who were admitted for pregnancy follow- -up and vaccination services, which are mandatory in FHCs. The unemployment status (73.2\%) was also compatible with the number of women and female employment. Medication use increases with age. The prevalence of hypertension (14\%) was compatible with the community. According to 2015 data from Directorate General for Health Services of Public Health Institution of Turkey, an average of 8.0-9.5 annual healthcare visits correlates with the $31 \% \mathrm{FHC}$ admission ratio of the study group [14]. In this study, the distribution of the patients selected from the FHCs in proportion to the population registered to the family physicians located within the provincial boundaries shows that the data of the study represent the entire population of the province.

Health literacy is considered the main factor to determine the health status of individuals, as compared to the other factors such as income level, employment status, education level, and race and ethnicity $[1,7]$. The health literacy levels could be as variable as the health status of individuals among countries. According to studies conducted in different countries, one out of every ten people (12\%) in eight European countries [9], two out of every ten people (24.5\%) in Turkey [13], six out of every ten people $(61 \%)$ in South Korea [15], and almost nine out of every ten people (88\%) in the United States [8] reported that the healthcare system in these countries was not beneficial due to the lack of health literacy. The healthcare providers in these countries were unable to navigate the healthcare system successfully. In this study, the health literacy level was found to be inadequate in three out of every ten patients (27.5\%). The result was inadequate and very similar to the result that was previously reported by Durusu-Tanriöver et al. [13]. The health literacy level of the participants in Eskisehir was lower than that of participants in South Korea and America. Interestingly, the health literacy level of the participants in Europe was 15.5\% lower than that of the participants in Eskisehir. In addition, the levels of health literacy of individuals might differ when studies are conducted in various regions of the same province. In our study, the health literacy level of the patients who were admitted to Odunpazari district FHCs were higher than that of the patients in the Tepebasi district FHCs. However, this difference in health literacy levels between the regions became negligible when the levels were analyzed with the inclusion of the other variables. This may be due to the fact that the Odunpazari region is one of the first settlements of the city and that the Tepebasi region is a relatively new region developing with increasing population growth and other characteristics of the study population, such as the socioeconomic level.

The participants in our study were adults ( $18+$ years old) and most of them had a family and/or dependents; therefore, they are expected to be inclined to seek health-related information and to be responsible for the health status of their family. In our study, the health literacy levels of the participants in the 36-45-year-old age group were higher than the participants in 
other age groups. However, the results of the regression analysis showed that increased age of the participants decreases the probability of a high level of health literacy by about 1-fold per year. Similarly, the studies indicated that the health literacy levels of patients over 45 years old were lower than that of other age groups $[16,17]$. In various studies, it was also reported that the health literacy level had a tendency to be higher in young age, while it decreased in older age groups. Higher age became an important indicator of inadequate health literacy $[6,13,15,18$, 19]. Including elderly people with low education level in a study might negatively impact the study results. Therefore, the health literacy evaluation should be performed by controlling for age variables in future studies. The development of personal health literacy knowledge and skills was found to be a life-long process.

Even highly educated individuals might have difficulty in obtaining care and understanding their healthcare systems, especially when their health condition makes them more vulnerable [1]. In this respect, high levels of education did not always mean high health literacy $[15,20]$. In our study, the level of health literacy was higher for those who had master's and higher degrees than the others. The level of health literacy was increased by 2.5-, 3.1-, and 3.3-fold for middle school graduates, high school graduates, and graduate university, respectively. Similarly, some studies have indicated that health literacy increases with the level of school education $[6,13,15,17,21]$ and that education plays a key role in the development of health literacy.

The people who work in any business are expected to be more inclined to seek health-related information as they have more opportunities to socialize and receive and exchange ideas. In this study, the health literacy level of the employed population was higher than the unemployed population's health literacy level. In the study conducted by Jovic-Vranes et al., the health literacy levels of employed people were also found to be higher than that of unemployed people [17]. However, in our study, this relationship was eliminated when analyzed with other variables. The impact of variables that have an opposite relationship on employment can be one of the reasons for this situation.

It was expected that the level of health literacy of people who were living in a city center/metropolitan area was high due to reasons such as easier access to health-related information and the high percentage of employment in city centers/metropolitan areas. In our study, the health literacy levels of the long-term inhabitants of a city center/metropolitan area were higher than those who lived in a village/town. Similarly, according to a study conducted at the two primary healthcare centers in Belgrade, the health literacy levels were higher in urban than in rural areas [17]. However, the difference obtained from urban versus rural data was eliminated when analyzed with other variables. The reasons for this situation included variables such as age, migration, education, working conditions, employment, occupational status, and cognitive status.

The people with a high level of health literacy have a greater tendency to seek health-promoting behaviors and to evaluate their health status better [19]. In this sense, the people who take responsibility for their health and develop healthy life behaviors are expected to be healthier. The health literacy levels of those who perceive the general health status as excellent/fairly good are higher than those who perceive their general health status to be good or average/poor. Similarly, there are studies reporting that health literacy levels of people with good health perception are high $[17,21]$. However, the difference arising from the perception of health status disappeared when analyzed with other variables.

Health literacy has a direct impact on health behavior and health status [18]. While health literacy has an impact on health behaviors, including many modifiable risk factors such as lack of physical activity, poor dietary habits, smoking, and alcohol use, these risky health behaviors are related to non-communicable diseases. Therefore, the people with low levels of health literacy are expected to be more prone to non-communicable diseases [1] and to have difficulty in developing the self-care skills required to control non-communicable diseases such as diabetes and hypertension $[16,20,22]$. In this study, the health literacy levels of people with diabetes or hypertension were found to be lower. Similarly, there are studies reporting on people with low levels of health literacy who were more likely to have diseases such as diabetes and hypertension $[6,16]$. Inadequate health literacy is seen as an obstacle to be overcome for each of the prevention, screening, and treatment stages of non-communicable diseases [22]. Similarly, in our study, the likelihood of having a high level of health literacy was found to be 1.5-fold higher in individuals who did not have a disease and did not require the regular use of medication. Again, our findings show that patients who did not see a family physician in the previous six months were 0.6 -fold more likely to have high levels of health literacy. Other determinants, such as regular medication use, frequent follow-ups, and having non-communicable diseases seem to coincide with low health literacy levels.

Those with low health literacy are expected to postpone their treatment because they do not receive transport services [23]. In this study, the health literacy levels of the people who were transported to FHCs by vehicle were higher than those who travelled on foot. However, the difference arising from the way of transportation to FHCs was eliminated when analyzed with other variables.

With pregnancy follow-up, being admitted to a healthcare service at regular intervals, the direct effect of behavior on health on the development of the fetus (understanding and evaluating the information) and reducing the risky situations in pregnancy according to follow-up are expected to increase the health literacy levels of pregnant women. However, since all procedures in vaccination services are a technical knowledge bundle, this eliminates the possibility of people understanding and using the information. As a reflection of this thought, the health literacy levels of people who were admitted to FHCs during pregnancy follow-up were found to be higher. However, the reason for admitting to the FHCs was eliminated when analyzed with other variables.

Primary healthcare is seen as an environment in which potential inequalities in health literacy can be mitigated [11]. However, in our study, the likelihood of having adequate health literacy levels among the patients who were most frequently admitted to private hospitals/clinics firstly in case of any health problem or disease were found to be 2.7 -fold higher. It is seen that health literacy levels have an effect on health services usage or preferences. One of the reasons for this situation may be that people who prefer private hospitals/clinics are generally more likely to be in a better economic situation.

More time spent in the healthcare system can be considered as an indication that a patient cannot find a solution to his/ /her problem and has received a low-quality service [13]. In this respect, there is a link between the level of health literacy and the frequency of healthcare system use. Health literacy levels of people who visit a health institution on average $\leq 6$ times for any health-related problem were found to be higher than those who had more admissions $(p<0.001)$. Similar results have been reported in various studies $[19,24]$. However, the difference between the admission frequencies was also eliminated when analyzed with other variables. This may be explained by the fact that people with low health literacy levels use therapeutic health services more frequently and preventive health services less often [19].

\section{Limitations of the study}

This study aimed to determine the levels of health literacy and the variables that affect it. Thus, how providers should proceed to improve health literacy, linked to health outcomes could not be determined. 
No individuals that saw a doctor outside of preventive medicine (pregnancy follow-up, wound dressing, and vaccination) were included; thus, comparisons across preventive and therapeutic health outcome could not to be made in this study.

The health literacy level measured in the study were limited to scales.

The patient's distribution to avoid to selection bias: 5-6 patients were selected per family physician according to the proportion of the registered population. No polyclinic services with institutional preferences were included.

\section{Conclusions}

In conclusion, together with an unchangeable factor like age, the modifiable factors such as the level of education, the presence of a disease requiring regular use of medication, the most frequently referenced health institution, and a family medicine admission within six months stand out as the determinants of inadequate health literacy or important variables to be considered in order to increase health literacy. Future studies are recommended to address health literacy by controlling age and education variables as patient profile and focusing on how providers should behave to improve health literacy associated with better health outcomes.

Acknowledgements. The authors are grateful to the participants who made this study possible.

Source of funding: This work was funded from the authors' own resources.

Conflicts of interest: The authors declare no conflicts of interest.

\section{References}

1. Kickbusch I, Pelikan JM, Apfel P, et al. (eds.). Health literacy. The solid facts. Copenhagen: WHO Regional Office for Europe; 2013.

2. Harnett $S$, Morgan-Daniel J. Health literacy considerations for users of complementary and alternative medicine. J Consum Health Internet 2018; 22(1): 63-71, doi: 10.1080/15398285.2018.1415593.

3. Berkman ND, Sheridan SL, Donahue KE, et al. Low health literacy and health outcomes: an updated systematic review. Ann Intern Med 2011; 155(2): 97-107, doi: 10.7326/0003-4819-155-2-201107190-00005.

4. MacLeod S, Musich S, Gulyas S, et al. The impact of inadequate health literacy on patient satisfaction, health care utilization, and expenditures among older adults. Geriatr Nurs 2017; 38: 334-341, doi: 10.1016/j.gerinurse.2016.12.003.

5. Yılmazel G, Çetinkaya F. Sağlık okuryazarlığının toplum sağlığı açısından önemi. TAF Preventive Medicine Bulletin 2016; 15(1): 69-74, doi: 10.5455/pmb.1-1448870518 (in Turkish).

6. Peterson PN, Shetterly SM, Clarke CL, et al. Health literacy and outcomes among patients with heart failure. JAMA 2011; 305(16): 1695-1701, doi: 10.1001/jama.2011.512.

7. Santos P, Sa L, Couto L, et al. Health literacy as a key for effective preventive medicine. Cogent Soc Sci 2017; 3: 1407522, doi: $10.1080 / 23311886.2017 .1407522$.

8. Eigelbach B. Ten suggested health literacy attributes of a health care organization. J Consum Health Internet 2017; 21(2): 201-208, doi: 10.1080/15398285.2017.1311606.

9. Sørensen K, Pelikan JM, Röthlin F, et al. Health literacy in Europe: comparative results of the European health literacy survey (HLS-EU). Eur J Public Health 2015; 25(6): 1053-1058, doi: 10.1093/eurpub/ckv043.

10. Hersh L, Salzman B, Snyderman D. Health literacy in primary care practice. Am Fam Physician 2015; 92(2): 118-124.

11. Aoki T, Inoue M. Association between health literacy and patient experience of primary care attributes: a cross-sectional study in Japan. PLOS ONE 2017; 12(9): e0184565, doi: 10.1371/journal.pone.0184565.

12. Okyay P, Abacıgil F, Harlak H. Türkiye sağlık okuryazarlığı ölçeği-32. Türkiye sağlık okuryazarlığı älçekleri güvenirlik ve geçerlilik çalışması (Vol. 1). Ankara: Anıl Reklam Matbaa; 2016 (in Turkish).

13. Durusu-Tanrıöver M, Yıldırım HH, Demiray-Ready FN, et al. Türkiye sağlık okuryazarlığı araştırması (Vol. 1). Ankara: Sağılı-Sen Yayınları; 2014 (in Turkish).

14. Köse MR, Bora-Başara B, Güler C, et al. Republic of Turkey Ministry of Health Health statistics yearbook 2015. Ankara: Sistem Ofset Basım Yayın San. ve Tic. Ltd. Şti.; 2016.

15. Jeong SH, Kim HK. Health literacy and barriers to health information seeking: a nationwide survey in South Korea. Patient Educ Couns 2016; 99: 1880-1887, doi: 10.1016/j.pec.2016.06.015.

16. Saeed H, Saleem R, Naemm R, et al. Impact of health literacy on diabetes outcomes: a cross-sectional study from Lahore, Pakistan. Public Health 2018; 156: 8-14, doi: 10.1016/j.puhe.2017.12.005.

17. Jovic-Vranes A, Bjegovic-Mikanovic V, Marinkovic J. Functional health literacy among primary health-care patients: data from the Belgrade pilot study. J Public Health 2009; 31(4): 490-495, doi: 10.1093/pubmed/fdp049.

18. Sun $X$, Shi $Y$, Zeng $Q$, et al. Determinants of health literacy and health behavior regarding infectious respiratory diseases: a pathway model. BMC Public Health 2013; 13(261): 1-8, doi: 10.1186/1471-2458-13-261.

19. Schaeffer D, Hurrelmann K, Bauer U, et al. National action plan health literacy. Promoting health literacy in Germany. Berlin: KomPart; 2018.

20. Shi D, Li J, Wang Y, et al. Association between health literacy and hypertension management in a Chinese community: a retrospective cohort study. Intern Emerg Med 2017; 12: 765-776, doi: 10.1007/s11739-017-1651-7.

21. Tokuda Y, Doba N, Butler JP, et al. Health literacy and physical and psychological wellbeing in Japanese adults. Patient Educ Couns 2009; 75: 411-417, doi: 10.1016/j.pec.2009.03.031.

22. Magnani JW, Mujahid MS, Aronow HD, et al. Health literacy and cardiovascular disease: Fundamental relevance to primary and secondary prevention. Circulation 2018; 138(2): e48-e74, doi: 10.1161/CIR.0000000000000579.

23. Levy H, Janke A. Health literacy and access to care. J Health Commun 2016; 21(1): 43-50, doi: 10.1080/10810730.2015.1131776.

24. Berens EM, Vogt D, Ganahl K, et al. Health literacy and health service use in Germany. Health Lit Res Pract 2018; 2(2): 115-122, doi: 10.3928/24748307-20180503-01.

Tables: 4

Figures: 1

References: 24

Received: 05.03.2021

Reviewed: 23.03.2021

Accepted: 20.05 .2021
Address for correspondence:

Özgül Örsal, Ph.D.

Eskisehir Osmangazi University

Eskisehir

Turkey

Tel.: +90 5534499771

E-mail: oorsal@ogu.edu.tr 